\title{
Efeitos da corrosão atmosférica nas empresas do Porto do Açu cinco anos após o início das operações
}

\author{
Luiz Guilherme da Silva ${ }^{1}$ \\ Henrique Rego Monteiro Da Hora ${ }^{2}$ \\ Milton Erthal Junior ${ }^{3}$
}

\begin{abstract}
RESUMO
Os sais presentes na atmosfera dos ambientes costeiros, quando associado ao tempo e a humidade, causam a oxidação de alguns materiais. Os prejuízos econômicos ocasionados pela corrosão são estimados em $3 \%$ do PIB mundial e o uso de tecnologias preventivas pode reduzir de $20 \%$ a $25 \%$ deste custo. Este trabalho tem o objetivo de avaliar o impacto da corrosão atmosférica nas empresas instaladas no Porto do Açu, localizado no município de São João da Barra, RJ. A pesquisa foi conduzida por aplicação de questionários junto aos gestores de três empresas em atividade há mais de cinco anos no porto. Buscou elencar informações sobre o impacto financeiro, material, saúde das pessoas e as ações preventivas e corretivas associadas aos efeitos da corrosão atmosférica. Na opinião dos gestores os prejuízos causados pela corrosão nas empresas são de nível intermediário (nota $=3$ ), em uma escala de 1 a 5 . Cerca de $50 \%$ dos impactos estão associados a infraestrutura, $30 \%$ em peças e $20 \%$ em equipamentos. A estimativa nos custos gerais das empresas com a manutenção preventiva e corretiva (reposição de peças e equipamentos danificados) ainda não são totalmente compreendidos pelos gestores. Este trabalho faz o primeiro levantamento deste aspecto no Complexo Industrial do Porto do Açu. Os dados sugerem que o problema da corrosão atmosférica pode não ter sido adequadamente avaliado pelas empresas em operação. A implantação de técnicas específicas de prevenção e controle de corrosão atmosférica faz-se necessária no Porto do Açu.
\end{abstract}

PALAVRA-CHAVE: Maresia, Corrosão, Gestão Portuária.

\section{ABSTRACT}

The salt in the atmosphere of coast environment, when in association with the time and humidity, can cause the oxidation of some materials. The economic losses by the corrosion are estimated in $3 \%$ of the world GDP and the use of preventive technologies could save $20 \%$ to $25 \%$ of this cost. The goal of this work is evaluate the impact of the atmospheric corrosion at Açu Port companies, located in São João da Barra, Rio de Janeiro, Brazil. A survey was conducted with managers of three companies in operation more than five years in the port. Information about the financial, material and health impact, beyond preventive and corrective strategies were obtained. As the manager's opinion the losses caused by the corrosion on the companies has an intermediate level (grade = 3), on a scale from 1 to 5 . Infrastructure represents $50 \%$ of the impacts, $30 \%$ are parts and tools and $20 \%$ are equipments. The general cost to the companies to preventive and corrective maintenance with replacement of pieces and equipment damaged are not yet fully understood by managers. This research does the first data survey about the corrosion at Industrial Complex of Açu Port. The data suggest that the companies didn't adequately consider this trouble. The implementation of specific techniques for prevention and control of the atmospheric corrosion must be necessary in the Port of Açu.

KEYWORDS: Sea air, Corrosion, Port Management.

1 Aluno do Mestrado Profissional em Sistemas Aplicados a Engenharia e Gestão, Campos dos Goytacazes, RJ.SAEG/IFF, Campos dos Goytacazes, Brasil. MBA Gerenciamento de Projetos-FGV, Engenheiro Mecânico-UFF. E-mail: Iguilhermes@hotmail.com

2 Professor do Instituto Federal Fluminense, Mestrado Profissional em Sistemas Aplicados a Engenharia e Gestão, Campos dos Goytacazes, RJ, Brasil. E-mail: dahora@gmail.com

3 Professor do Instituto Federal Fluminense, Mestrado Profissional em Sistemas Aplicados a Engenharia e Gestão, Campos dos Goytacazes, RJ, Brasil. Professor da Universidade Candido Mendes, Mestrado Profissional em Pesquisa Operacional e Inteligência Computacional e Doutorado em Planejamento Regional e Gestão da Cidade, Campos dos Goytacazes. *Autor para correspondência: miltonerthal@hotmail.com 


\section{1- Introdução}

A ferrugem, nome pelo qual a corrosão é mais conhecida, tem registros históricos quanto aos seus efeitos negativos para a sociedade, pelas restrições que este fenômeno causa na economia. Em 1627 Robert Boyle deu início aos estudos das causas da corrosão. Os conceitos modernos sobre este tema se iniciam com as importantes contribuições, a partir de 1923, com Ulick Richardson Evans, Herbert H. Uhlig, e Mars G. Fontana (AHMAD, 2006, pag. 1).

A corrosão, segundo Fontana (1986, pag. 4), pode ser definida como a deterioração de materiais causado por reações químicas ou eletroquímicas com o meio ambiente. A ação corrosiva da atmosfera está associada as variações do clima (umidade relativa, temperatura e a intensidade e direção dos ventos), a presença de substâncias poluentes (particulados e gases) e ao tempo de exposição do material metálico (GENTIL, 2011). Os efeitos da corrosão atmosférica são mais acentuados nos ambientes costeiros, onde a atmosfera marinha, devido a ação dos ventos, transporta para a costa a névoa do mar carregada de sais. Este fenômeno é conhecido como maresia, que devido a deposição de sais em superfícies, associado ao tempo e a humidade, irá causar a oxidação destes materiais. Este impacto pode ser mais acentuado nas áreas acima do nível do mar, pois ficarão expostas aos ciclos de humidade e seca. A corrosão atmosférica é responsável por grande parte do consumo de aço produzido no mundo, usado para repor perdas diretas, provocadas pela corrosão, causando forte impacto econômico (ROBERGE, 2008, pag. 331).

Muitos trabalhos, nacionais e internacionais, tratam do assunto corrosão, no entanto, estudos específicos em regiões portuárias juntamente com complexos industriais ao seu redor ainda são pouco explorados (NATESAN et al., 2008). A maioria dos trabalhos estão voltados para as análises de danos causados pela corrosão em estruturas de concreto armado, cais, quebra-mares e com as recomendações para ações preventivas, corretivas, programas de manutenção, novas práticas para controle e combate à corrosão. Como o trabalho de Peixoto (2014) no Porto de Leixões, em Portugal, que trata de estruturas como blocos, caixões e pilares.

Um grupo de especialistas internacionais vinculados ao Association for Waterborne Transport Infrastructure e ao Permanent International Association of Navigation Congress (PIANC) recomenda que o gerenciamento da corrosão de estruturas portuárias seja feito sob a ótica do Life Cicle Management (LCM) (PORT TECHNOLOGY GROUP, 2009). A associação PIANC fornece orientações especializadas e aconselhamento técnico, econômico e ambiental relacionados à infraestrutura de transporte aquático. O LCM é uma abordagem gerencial do projeto, considerando a construção da infraestrutura, operação, manutenção e revitalização. Alguns portos adotam esta estratégia para maximizar suas receitas. A metodologia do Whole Life Cost (WLC) aplica-se para um mínimo custo de vida total da infraestrutura, pois considera custos de estruturação, conservação e os custos indiretos (MARCOM WORKING GROUP, 2008, pag. 7).

O Brasil, devido a sua diversidade de climas e condições atmosféricas apresenta na maior parte do seu território condições propícias a corrosão atmosférica (VIANNA, 1980). O conhecimento relativo aos danos da corrosão nas estruturas metálicas das áreas portuárias, tais como galpões, maquinários, peças, estoques, produtos e processos ainda é pouco explorado. Alguns trabalhos relatam sobre testes em amostras de diferentes materiais para determinar a taxa de corrosão e perda de material (NATESAN et al., 2006), mas sem definir onde, exatamente, a corrosão ocorre. A indisponibilidade de dados históricos sobre o impacto da corrosão nas estruturas metálicas nas regiões portuárias do Brasil dificulta uma compreensão exata sobre este tema nos portos industriais, como é o caso do Porto do Açu. As empresas instaladas neste complexo portuário diagnosticaram este problema? Como estas empresas estão reagindo para lidar com o problema da corrosão atmosférica em suas estruturas, processos e produtos?

Para responder estas questões de pesquisas, o objetivo deste trabalho foi realizar o primeiro levantamento de dados sobre os impactos provocados pela corrosão atmosférica marítima (maresia) nas empresas instaladas na região do Porto do Açu, localizado no município de São João da Barra/RJ. 


\section{1- Custos da corrosão}

Acima de 3\% do PIB mundial, o custo da corrosão atinge os US\$2 trilhões e aplicações de técnicas de controle da corrosão poderiam economizar de 20 a 25\% deste custo (HAYS, 2015, pag. 1). Nos EUA, entre os anos de 1999 e 2001, estima-se um custo direto provocado pela corrosão da ordem de US\$ 276 bilhões, que equivale a 3,1\% do PIB deste país e um custo indireto anual igual ao custo direto, elevando o custo anual para US\$552 bilhões (KOCH, 2002, pag. 3). Na China, dados de 2014 demonstraram um custo total anual com a corrosão da ordem de 2,127 bilhões $\mathrm{RMB}$, que representa 3,34\% do PIB. Só nas áreas portuárias os custos atingiram 2,63 bilhões $\mathrm{RMB}, 2,44$ bilhões RMB em investimentos anticorrosão em novas construções e 0,19 Bilhões RMB com manutenção relativa a corrosão (HOU, 2017, pag. 1-5). No ano de 2015 estima-se que no Brasil o custo anual com a corrosão represente 4\% do PIB (GRANDES CONSTRUÇÕES, 2017). Segundo dados da Resolução 2969, ANTAQ - Agência Nacional de Transportes Aquaviários - de 4 de julho de 2013 o Brasil tem um total de 235 instalações portuárias, públicas e privadas, tanto marítimas quanto fluviais, sendo 135 marítimas, as quais estão suscetíveis a sofrer todo o impacto da corrosão atmosférica marinha.

\section{2- Porto do Açu}

Com capacidade de movimentação de granel sólido, coque, carvão, bauxita, rochas ornamentais, containers, petróleo, diesel e óleo marítimo o empreendimento conta com 3 terminais portuários: T-MULT (para multicargas), T-OIL (para petróleo) e o TECMA (para óleo diesel marítimo e óleo combustível marítimos) (PORTO DO AÇU, 2018). O Superporto do Açu está localizado no Norte Fluminense, na cidade de São João da Barra/RJ e foi um projeto realizado pelo grupo EBX do empresário Eike Batista com investimentos da ordem de $\mathrm{R} \$ 10$ bilhões e tem o conceito de porto-indústria. Ocupa uma área de $130 \mathrm{~km} 2$, dos quais $90 \mathrm{~km} 2$ são de retroarea. É um porto $100 \%$ privado e atualmente é administrado pela PRUMO Logística Global, criada em 2007 e desde 2013 controlada pelo fundo norte americano ElG Global Energy Partners que investiu US\$780 milhões na PRUMO. Atualmente, a PRUMO conta com a parceria do Porto de Antuérpia, localizado em Flandes na Bélgica, outro complexo porto indústria, que traz conhecimento e expertise para ajudar a PRUMO no desenvolvimento do negócio. O Porto do Açú iniciou suas operações em 2014 e em desenvolvimento constante já conta com mais de 10 empresas em operação (PORTO DO AÇU, 2018).

Em sustentabilidade a PRUMO tem dentre suas ações a instituição voluntária da Reserva Particular do Patrimônio Natural Caruara, RPPN Caruara, com quase $40 \mathrm{~km}^{2}$, sendo a maior reserva privada de proteção da fauna e flora de restinga do país, onde são possíveis estudos científicos em parceria com diversas instituições, como Jardim Botânico, UERJ, UENF, UFF. Esta área gera ICMS Verde que já rendeu ao Município de São João da Barra mais de $\mathrm{R} \$ 3$ milhões em impostos ecológicos (PRUMO, 2019). A Figura 1 mostra a delimitação aproximada da Reserva Caruara e as delimitações aproximadas do Complexo Industrial do Porto do Açu, formado pelas áreas do DSJB - Distrito Industrial de São João da Barra em conjunto com a ZIPA - Zona industrial do Porto do Açu. 
Figura 1 - Limites do Município de São João da Barra (linha laranja) e delimitações aproximadas do Distrito Industrial de São João da Barra - DISJB (linha azul), da Zona Industrial do Porto do Açu ZIPA (linha amarela) e também da Reserva Particular do Patrimônio Natural Caruara - RPPN (linha vermelha).

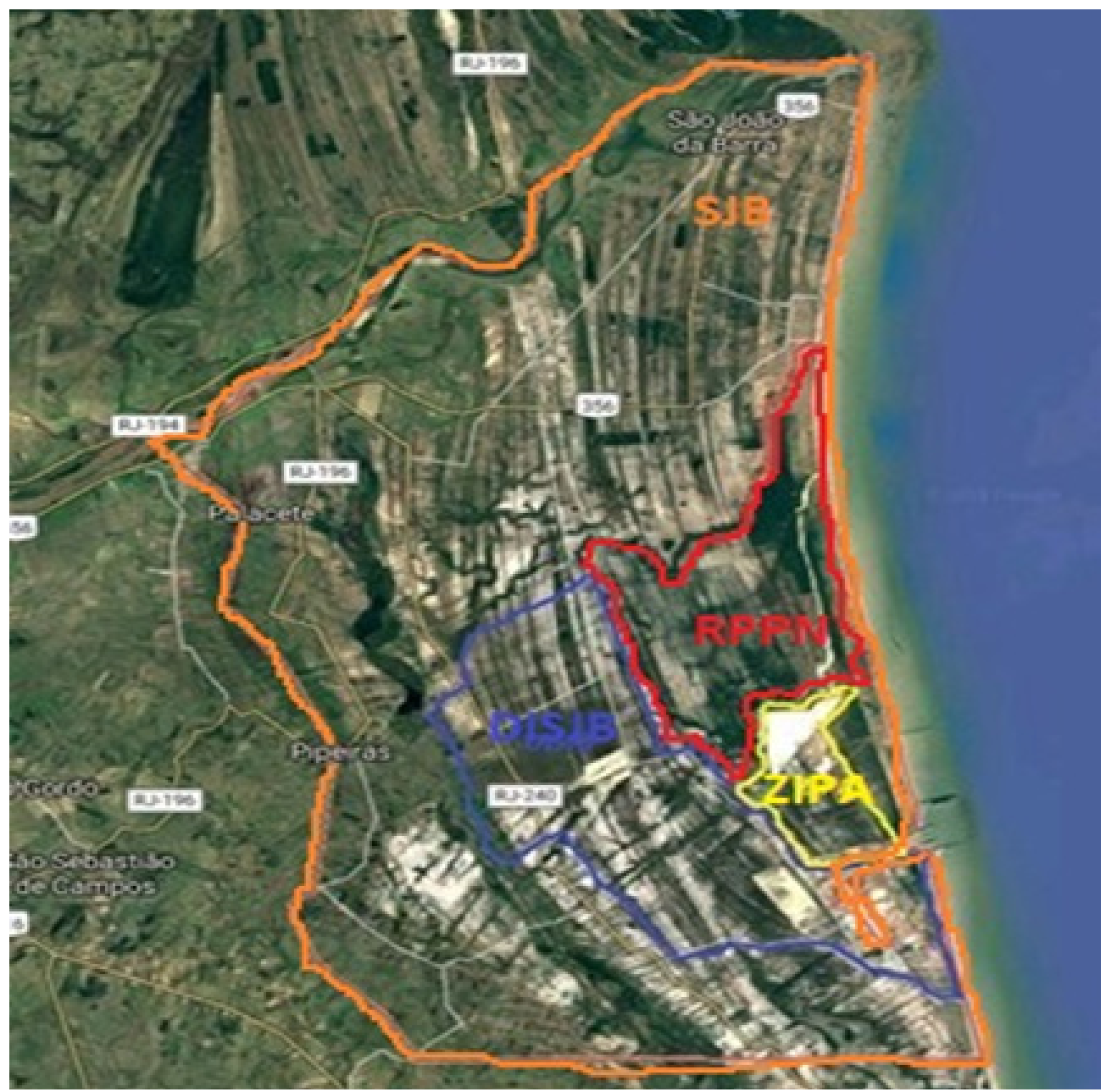

Fonte: os autores.

\section{2- Metodologia}

A pesquisa foi conduzida por metodologia observacional que, segundo Gil (2008), é aquela onde "no estudo por observação apenas observa algo que acontece ou já aconteceu", ou seja, no caso da pesquisa o impacto financeiro e material causado pela corrosão. As empresas estudadas foram analisadas em uma avaliação exploratória dos itens com sinais de corrosão atmosférica. Foi realizado um registro fotográfico, com aparelho celular (modelo iPhone 5S), de equipamentos, material de infraestrutura, itens de segurança, bens patrimoniais com danos causados pela corrosão. Atualmente, 10 empresas encontram-se em atividade no complexo portuário do Açu, localizadas a uma distância de 1,5 a $2 \mathrm{~km}$ da costa. Os questionários foram encaminhados para os gestores de todas as 10 empresas, mas houve retorno de apenas três, justamente as com maior facilidade de acesso e mais expressivas em termos de área construída e número de funcionários. As empresas pesquisadas iniciaram suas operações em 2014. Ao todo foram aplicados 15 questionários.

Para avaliar a percepção dos gestores, quanto aos impactos da corrosão em suas empresas 
foi realizada uma pesquisa exploratória, com um levantamento de dados através da aplicação de questionários, onde os gestores puderam responder também sobre questões relativas ao impacto financeiro e social, visto que diferente do impacto material não estão às vistas e ao gerenciamento de todos. O questionário foi elaborado com 16 questões, sendo 06 questões abordando sobre custos para manutenção, prevenção, mão-de-obra. Outras 03 questões com abordagem para identificação das principais peças e equipamentos que são danificados pela corrosão bem como o impacto é percebido de forma geral. As demais questões buscam informação a respeito de uso de protetores, destino do material, peça ou equipamento danificado, qual o nível de importância dado ao assunto dentro das empresas e se nos projetos de construção foram considerados estes possíveis impactos da corrosão atmosférica.

Para algumas questões foi considerada a escala de Likert contemplando 5 alternativas para afirmação: concordo totalmente, concordo parcialmente, não concordo nem discordo, discordo parcialmente, discordo totalmente, além de uma alternativa reservada ao direito do respondente de não opinar. Também foram elaboradas questões com somente afirmação (sim) ou negação (não) complementadas com alternativa de desconhecimento (não sei opinar) e direito de não opinar (não quero opinar). Para outras questões foi adotada uma escala de classificação 1 a 5, sendo 1-muito baixa, 2-baixa, 3-média, 4-alta, 5-muita alta. Foi realizado um pré-teste com 10 questionários com o objetivo de verificar sua eficácia no levantamento dos dados, assim poder validar o mesmo e segundo Gil, 2008 assegurar "clareza e precisão dos termos, forma de questões, desmembramento das questões, ordem das questões, introdução do questionário".

\section{3- Resultados}

A pesquisa observacional, feita por registro fotográfico, identificou alguns materiais em processo de deterioração no ambiente do Complexo Industrial do Porto do Açu. Este registro corrobora a opinião dos gestores das empresas pesquisadas quanto aos materiais mais atingidos pela maresia: calhas de chuva, telhados, cercas, painéis, tubulações e patrimônio em geral. As consequências da maresia incluem: a necessidade de substituição dos itens atingidos, contratação de serviço externo para realização da atividade de manutenção corretiva e perda de patrimônio. Em alguns casos os problemas apontados são acentuados devido a falha de projeto, como o uso de materiais de baixa resistência à corrosão para ambientes costeiros e regiões portuárias (Figura 2).

Figura 2 - Aspectos da corrosão atmosférica em instalações e equipamentos de empresas instaladas no Porto do Açu. a) calhas de chuva, b) cercas, c) engate rápido em área externa, d) telhas de fechamento de galpão, e) armários, f) tubulações, g) painel elétrico, h) estruturas de portas metálicas.

a)

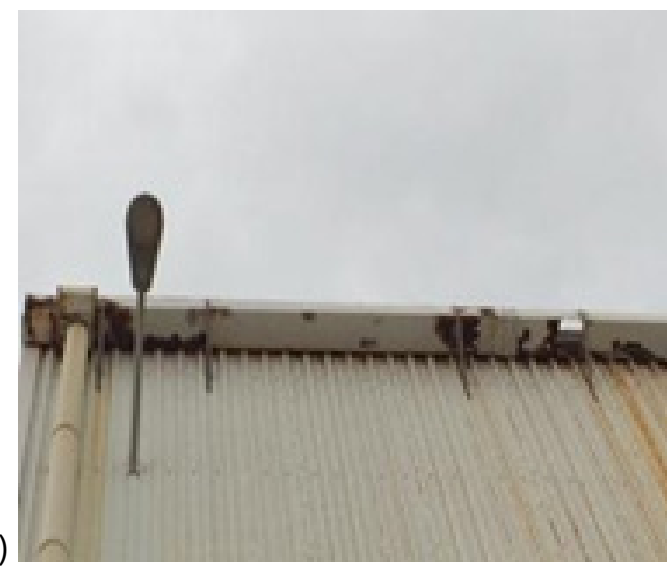

b)

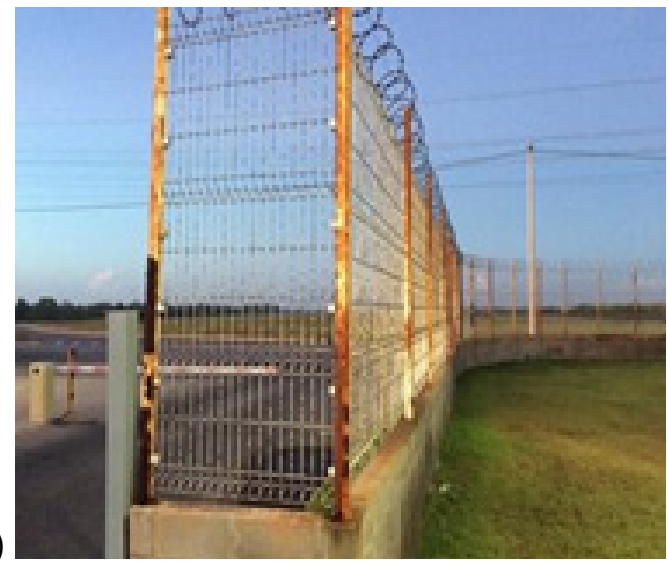



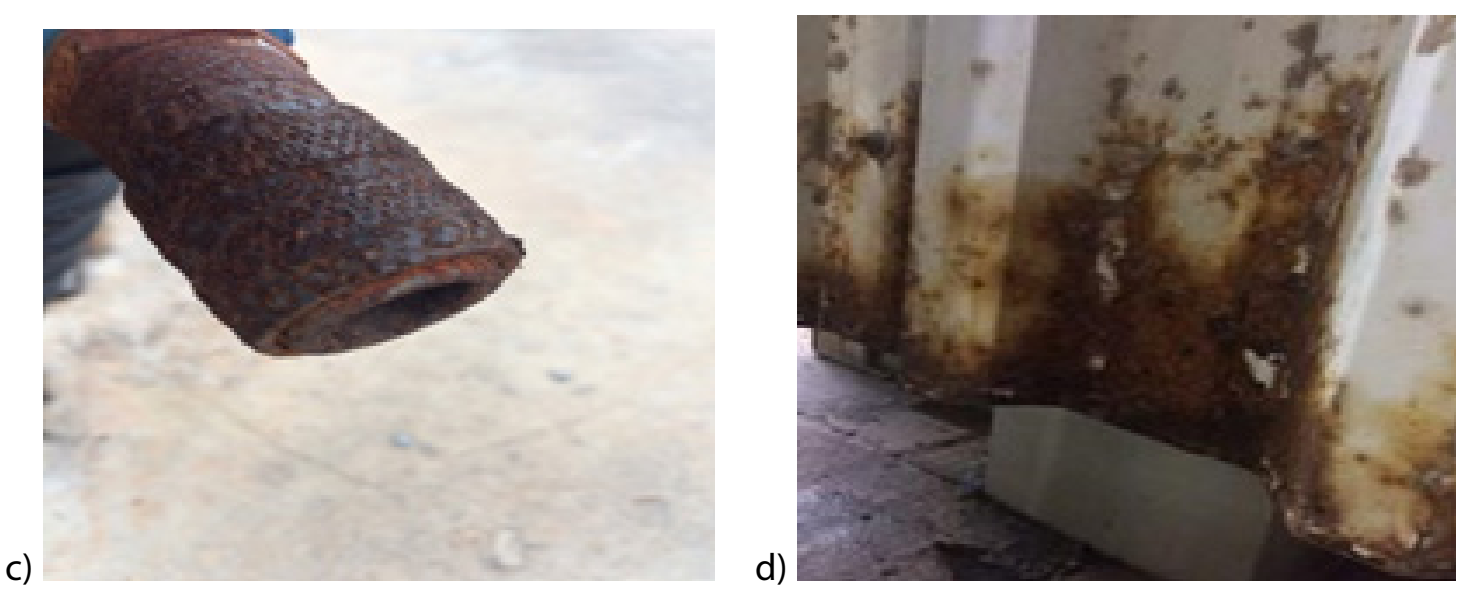

e)
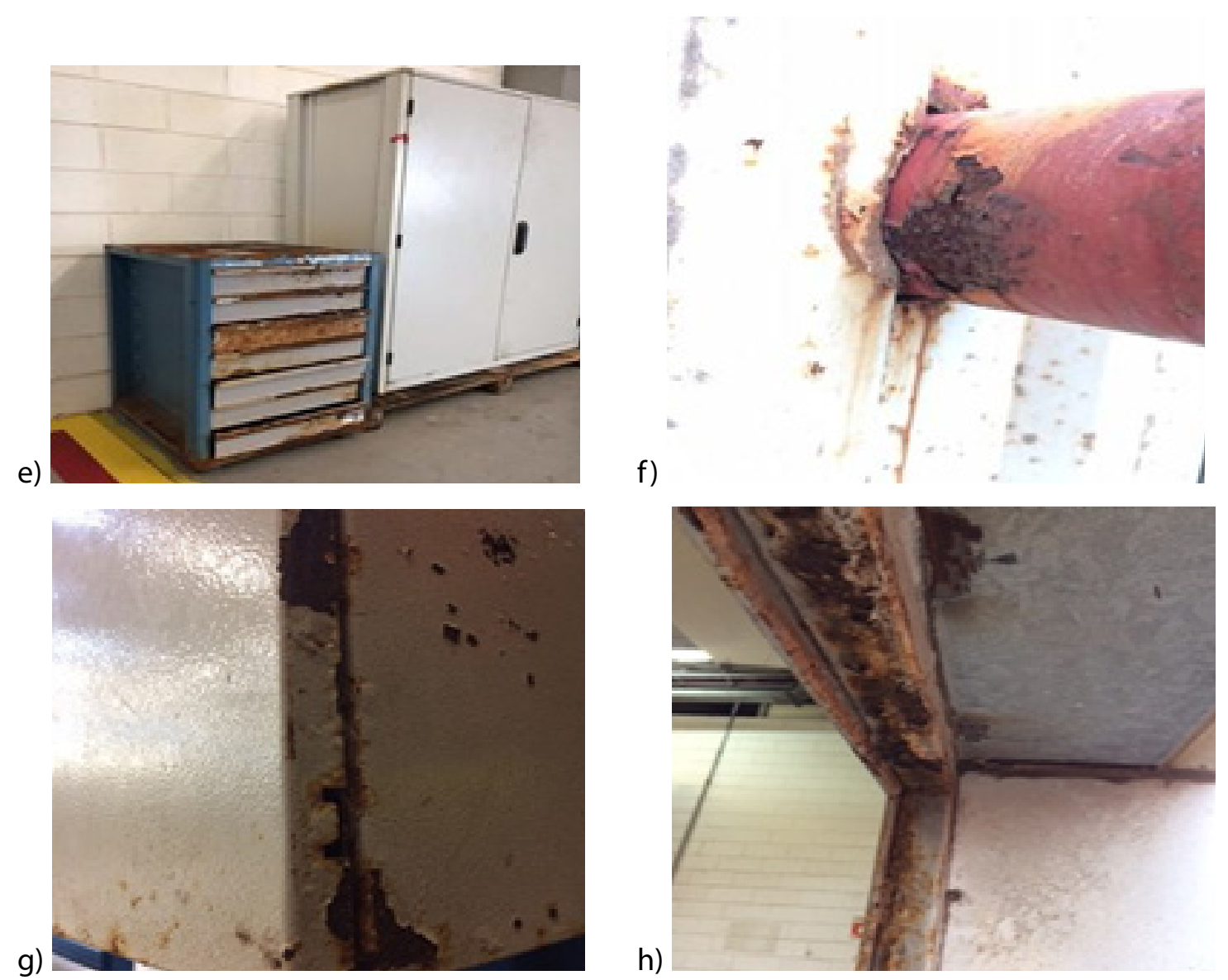

Inicialmente, o questionário buscou entender alguns aspectos gerais sobre os impactos da maresia nas empresas instaladas no Porto do Açu. Estes questionamentos abordaram sobre a importância dada pelas empresas, o nível dos prejuízos gerais, o impacto na vida útil de peças e equipamentos, a necessidade de manutenção corretiva e preventiva contra a corrosão. Na opinião dos gestores o grau de importância variou entre baixo e alto, com média e desvio padrão de 3,2 $\pm 1,6$. Este valor intermediário do grau de importância justifica a falta de ações preventivas das empresas e consequentes prejuízos econômicos. O levantamento do grau de prejuízos gerais causados à empresa foi de médio a alto $(3,6 \pm 1,2)$. Os impactos nos equipamentos foram considerados entre baixo e alto $(3,4 \pm 1,2)$. Na opinião dos gestores, as paradas na produção, recondicionamento de peças e equipamentos, manutenção corretiva e preventiva foram classificadas entre baixa e média quanto ao grau de importância (Figura 3). Os valores obtidos, variando entre 3 e 4 quanto ao grau de importância, numa escala que varia de 1 a 5, mostram que o problema da corrosão atmosférica ainda 
não é um problema significativo para as empresas, pois ainda não afetam os processos produtivos de forma muito impactante.

Figura 3 - Avaliação de aspectos gerais relacionadas à maresia em empresas instaladas no Porto do Açu.

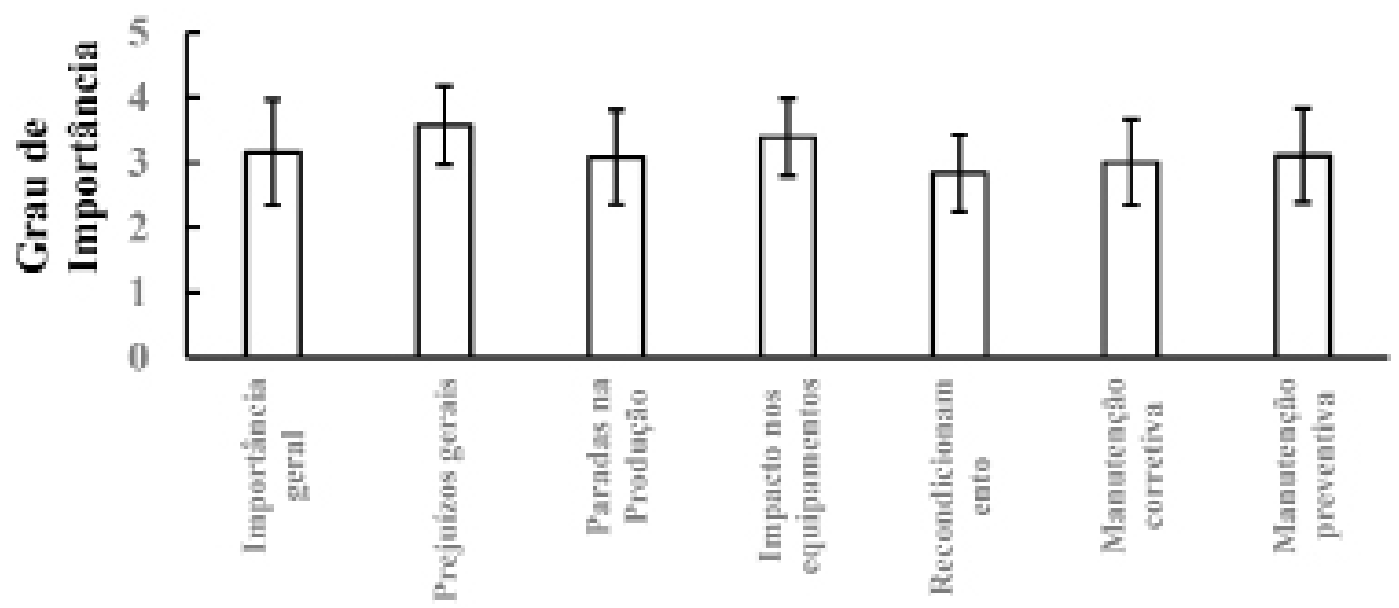

Na opinião dos gestores os efeitos da corrosão são mais intensos na infraestrutura da empresa ( $50 \%$ das respostas), nas peças e nos equipamentos (Figura 4).

Figura 4 - Porcentagem de corrosão em peças, equipamentos e infraestrutura.

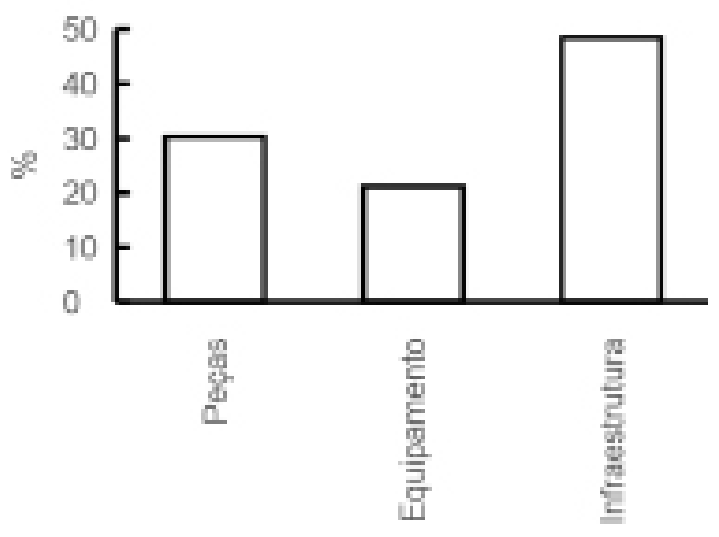

Porcas, parafusos, eixos e carenagens, além de outros acessórios são as peças mais afetadas pela corrosão. Entre os equipamentos mais afetados destacam-se os componentes elétricos, cabos de aço e itens de elevação, além de bombas e motores. Quanto aos itens da infraestrutura foram indicados os postes, luminárias, fechaduras, dobradiças, calhas de chuva, telhas, entre outros, que totalizam $24 \%$. Estes dados mostram que os equipamentos e as principais ferramentas de fabricação ainda não vem sendo atingidos de forma significativa pela maresia e que, por isso, ainda não tem se apresentando como um desafio para as empresas em seus processos produtivos, e aparentemente, ainda não impactam os produtos finais (Figura 5). 

cinco anos.

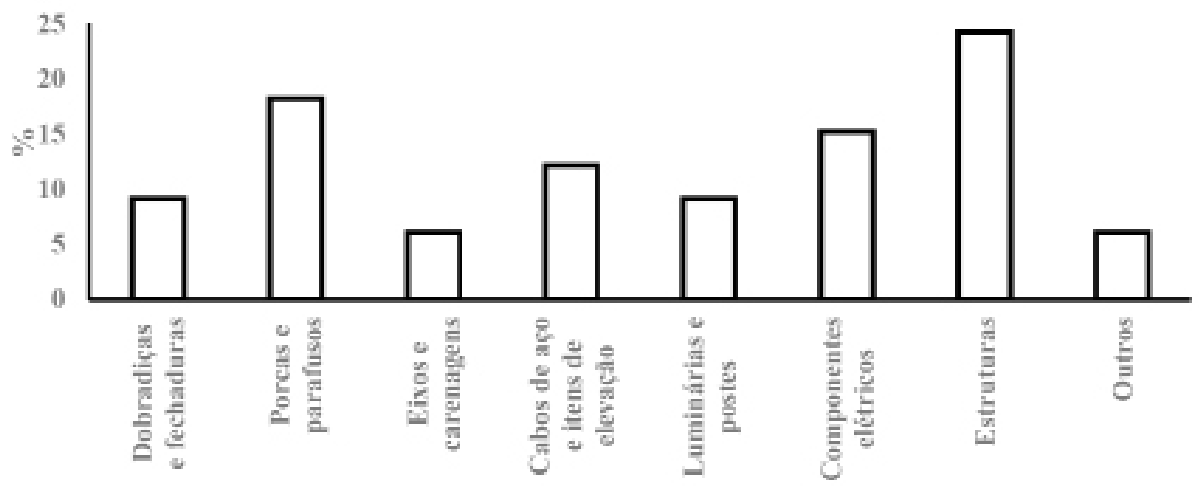

Para o levantamento dos custos os respondentes foram incentivados a informar em questões abertas, quanto ao valor mensal gasto, ou o percentual do custo mensal e ainda o seu impacto na lucratividade da empresa. Mais de $80 \%$ não responderam ou não souberam quantificar estes parâmetros. Os gestores não foram capazes de avaliar o investimento financeiro das empresas na manutenção e reposição de peças e equipamentos danificados com a corrosão. Estes também não souberam responder sobre os custos com a manutenção preventiva e sobre uma possível redução dos lucros mensais da empresa com as paradas na produção ocasionadas pela corrosão. É importante destacar que se tratando de dados financeiros, nem mesmo os gestores podem estar aptos a deixar tal informação explícitas e devem mantê-las em sigilo. A falta deste conhecimento pode impactar o planejamento financeiro das empresas, devido à falta de previsibilidade decustos ao longo dos anos. $\mathrm{O}$ problema da corrosão exige planejamento para despesas emergências não previstas e uso de técnicas apropriadas que busquem a minimização do problema da corrosão com uma visão de longo prazo. Apenas 33\% dos respondentes souberam informar sobre o tempo de mão-de-obra gasto com ações de manutenção preventiva e corretiva da corrosão. O tempo gasto em manutenção preventiva foi de $82 \pm 50 \mathrm{hh} /$ mês, enquanto que a mão-de-obra com ações de correção (apenas dois respondentes) foi estimada em $16 \mathrm{hh} / \mathrm{mês}$ e $30 \mathrm{hh} / \mathrm{mês}$.

O grau de impacto causado pela corrosão e pela maresia também foi avaliado buscando considerar a empresa como um todo e o impacto em infraestrutura apresenta-se como um impacto médio a alto, pois apresentou um resultado de 3,7 na média com um desvio padrão de 1,4. 0 impacto em estoques e em produtos apresentaram um nível de impacto de baixo a alto, visto que seus resultados demostraram médias de 3,4 e 3,3 respectivamente com desvio padrão de 1,6 para ambos. Também há impacto relativo às paradas nos processos, que se apresenta com nível baixo a médio, com média de 2,9 e desvio padrão de 1,6. O impacto na saúde foi o que apresentou menor nível, ficou com 1,7 na média e 1,3 no desvio padrão, ou seja, um grau de impacto de muito baixo a baixo (Figura 6).

Figura 6 - Grau de impacto causado pela maresia na infraestrutura, processos, produtos, ambiental, saúde e segurança do trabalhador nas empresas estudadas.

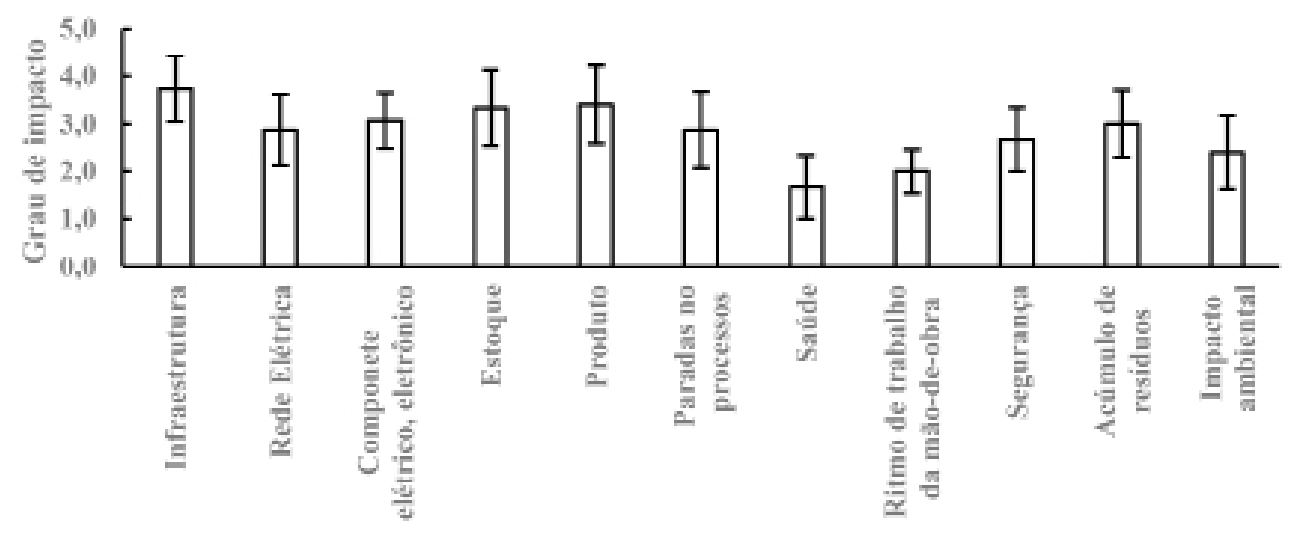


O questionário buscou aferir se o custo com o impacto causado pela corrosão havia sido previsto no custo do projeto e $80 \%$ dos respondentes responderam que desconhecem se havia tal previsão. Quando questionados sobre o que eles próprios mudariam nos projetos, visando a minimização dos efeitos da corrosão, sugeriu-se a construção de galpão galvanizado para armazenar peças, estoques e ferramentas expostas diretamente a maresia. $\mathrm{O}$ uso de materiais mais resistentes foi mencionado com frequência. Os respondentes também sugeriram ações que atuariam como prevenção à corrosão, como o uso de proteções catódica e anódica, pinturas especiais, definir meios de controle e implementar sistemas anticorrosão (Figura 7).

Figura 7 - Sugestões de alterações nos procedimentos e materiais a serem usados em projetos futuros, visando a prevenção da corrosão.

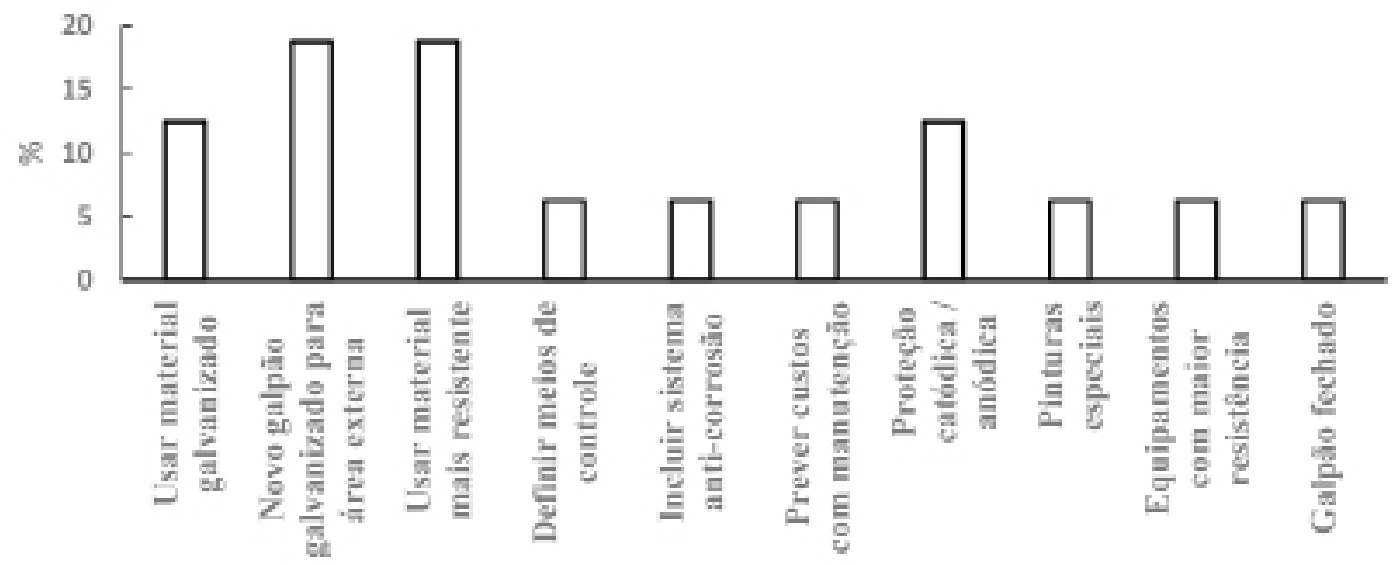

Sobre à concordância ou não sobre se o conhecimento prévio das despesas por perdas de peças corroídas, ações de proteção e ações de manutenção são importantes durante o desenvolvimento do projeto, $86 \%$ dos respondentes afirmaram que concordam totalmente, que este conhecimento é importante durante o desenvolvimento e implementação de projetos de construção. Como já mencionado anteriormente, custos com a corrosão podem ser reduzidos em até $25 \%$, desde que aplicadas técnicas de controle (HAYS, 2015, pag. 1). Como os resultados destas técnicas não demonstram de imediato um ganho pode ser que, por este motivo, as empresas do Porto do Açu, tenham optado em atuar somente quando o problema ocorre. Em uma questão com 14 alternativas para entender os impactos causados pela corrosão, os respondentes destacaram que o principal problema é a perda de produtividade nos processos e atrasos de entrega e multas, ambos com $29 \%$ de citação pelos respondentes. Além de impactos como danos ambientais, danos materiais e acidentes, que aparecem com $14 \%$. Os veículos, também são atingidos pela corrosão atmosférica, conforme citados por $10 \%$ dos respondentes (Figura 8).

Figura 8 - Impactos da corrosão observado em percentual.

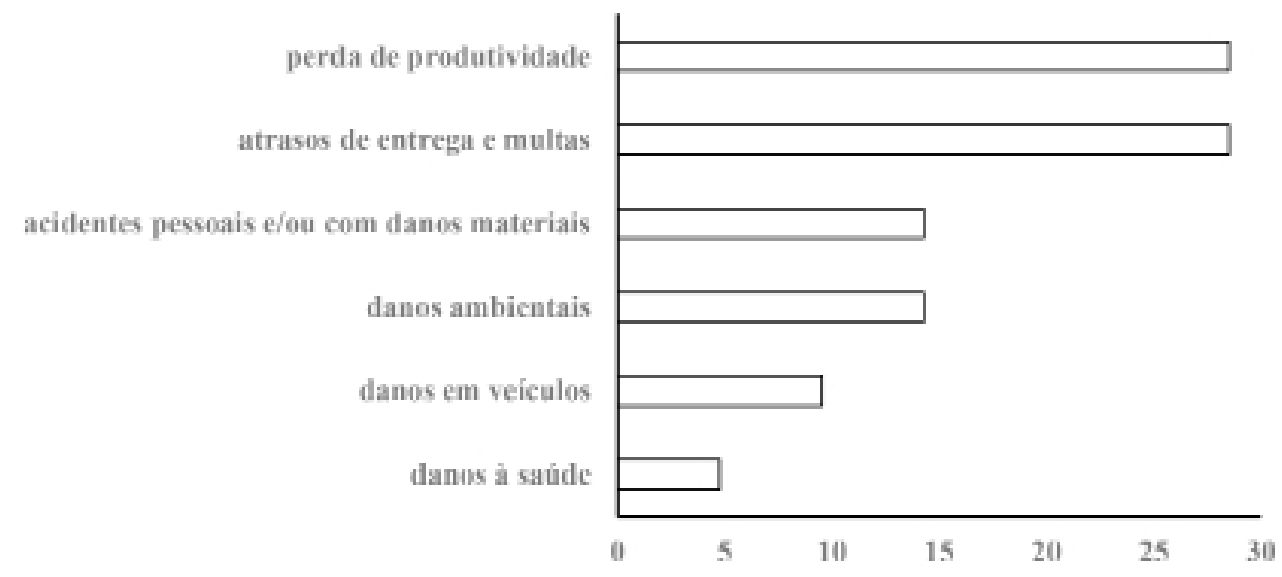


Na Figura 9 pode-se observar como as empresas estão reagindo aos efeitos da corrosão atmosférica. As ações mais frequentes são a aplicação de protetores, dentre eles tintas, vernizes, protetores spray, com $39 \%$ de citação nos questionários. Destacou-se também a reposição das peças corroídas por sobressalentes e substituição de partes danificadas, com $29 \%$ dos respondentes afirmando sobre esta ação. De maneira preventiva destaca-se a inspeção, manutenção preventiva, que aparece em terceiro com $19 \%$ dos respondentes.

Figura 9 - Reações das empresas contra a corrosão.

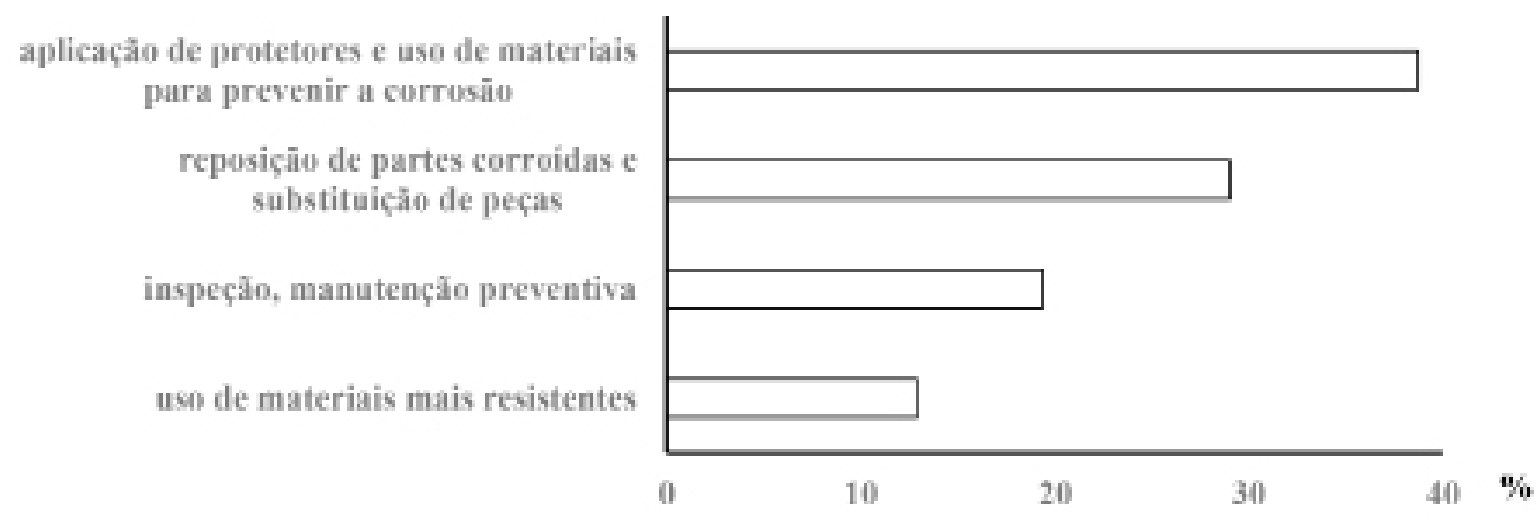

\section{Discussão}

Este trabalho buscou investigar algumas evidências sobre os impactos da corrosão atmosférica sobre os processos, os serviços, os estoques de matéria-prima, os produtos acabados, a infraestrutura metálica, os maquinários, os custos com manutenção e possíveis danos à saúde e meio ambiente nas empresas instaladas no Complexo Industrial do Porto do Açu. $\mathrm{O}$ ambiente onde as empresas estão instaladas, entre 1 e $2 \mathrm{Km}$ da costa, é caracterizado pela alta umidade relativa do ar, salinidade, exposição ao vento e mudanças de temperatura. Através da metodologia aplicada neste estudo pode-se evidenciar que estas condições adversas exigem a implantação de um sistema de gerenciamento específico para lidar com o problema da corrosão atmosférica.

Os resultados deste trabalho corroboram outros estudos sobre corrosão em regiões portuárias e a necessidade de implantação de técnicas de manutenção preventiva para este problema. Um estudo realizado em dois portos da Indonésia com testes em espécimes de aço carbono, aço galvanizado e alumínio, posicionados a $100 \mathrm{~m}$ da praia durante 30 dias, mostrou que a taxa de corrosão é mais intensa em amostras de aço carbono (taxa de corrosão de 38,5 mpy e 3,4 mpy) (NURAINI et al., 2018). No entanto, o aço galvanizado (taxa de corrosão de 4,8 mpy e $0.219 \mathrm{mpy}$ ) e o alumínio (taxas de 0,5181 mpy e 0,166 mpy) também são afetados. Neste mesmo estudo um coletor para levantamento da taxa de deposição de cloreto, que acelera a taxa de corrosão, mostrou que em um dos portos a taxa de deposição foi de $497 \mathrm{mg} / \mathrm{m}^{2}$ e no outro a taxa foi de $117 \mathrm{mg} / \mathrm{m}^{2}$. No Brasil, um trabalho realizado por PORTELLA e colaboradores (2012), realizado em 7 locais de Salvador, BA, mostra que o impacto da corrosão atmosférica nas amostras expostas na costa apresenta-se com a taxa de corrosão maior no aço carbono (1,2 - 3,14 mpy), seguida pelo cobre $(0,35 \mathrm{mpy})$ e, por fim, menor no alumínio $(0,1 \mathrm{mpy})$.

Neste presente estudo não foram considerados os efeitos da corrosão em estruturas que tem contato direto com a água do mar ou que estão imersos nela, como em cais, ductos, embarcações e blocos. No entanto, para fins de confirmação sobre a vulnerabilidade do aço carbono e aço galvanizado em ambientes costeiros o trabalho de PRIFIHARNI et al. (2018) realizado na Indonésia, mostra que os mesmos materiais são afetados no ambiente marinho. Após 27 dias 
de teste observou-se que o aço carbono apresentou maior perda de material e maior taxa de corrosão e que isso deve-se principalmente a salinidade e a taxa de oxigênio dissolvido.

A coleta de dados por meio de questionário mostrou-se adequada devido as dificuldades de obtenção, por outras fontes, de dados relativos às perdas diretas e indiretas como efeitos da corrosão atmosférica nas empresas envolvidas neste estudo. O sigilo por parte das empresas quanto a possível impacto financeiro relativo ao problema da corrosão no Porto do Açu dificulta a mensuração destas possíveis perdas financeiras. Esta condição se tornou uma limitação da metodologia aplicada neste estudo, que também tinha como um dos objetivos estimar em valores os gastos com corrosão nas empresas. A maior parte das perguntas do questionário direcionadas aos prejuízos financeiros causados pela corrosão não foram respondidas pelos gestores. Esta constatação abre possibilidade para que além do motivo de sigilo de dados financeiros há outra possibilidade que seria a falta de percepção dos gestores para este tema, e, portanto, não as mensuram. Muitos questionamentos demonstram uma possível falta de planejamento e de aplicação de práticas e técnicas específicas para gerenciar o impacto da corrosão atmosférica. Desta forma, a aplicação de questionário para avaliar o valor financeiro causado pela corrosão não foi satisfatória.

Segundo Gentil (2011) há uma tendência de que os custos com a corrosão se elevem com o tempo, tornando-se essencial que este problema seja avaliado ainda na fase de projeto de grandes instalações industriais. Pesquisas realizadas nos EUA mostram que o custo da corrosão em portos e vias chega aos US\$300 milhões/ano $(\mathrm{KOCH}$, et al, 2002, pag. 5) e pesquisas na China apontam para custos da ordem dos 190 milhões RMB em ações de manutenção (HOU, 2017, pag. 1-5). As empresas podem estimar os custos e se preparar previamente para os impactos financeiros da corrosão. As 4 principais abordagens para esse levantamento de custo da corrosão encontradas na literatura são o método Uhlig, através do cálculo do custo com base nos métodos de prevenção, o método Hoar, que realiza estimativas em vários setores industriais, o método I/O (input/output), baseado na matriz de entrada e saída e o método do custo do ciclo de vida - LCC (Life cycle costing), este faz uso do cálculo do VPL - valor presente líquido (BHASKARAN, 2005).

Grupos de pesquisa no Japão e Ásia tem indicado algumas considerações para a manutenção e prevenção da corrosão em Portos, que abordam desde o projeto inicial das estruturas, a sistematização de manutenção eficiente, não ignorar as condições do ambiente, os tipos de estruturas e seus materiais, além de afirmar a importância do conceito LCM - Life cycle management como base do programa de manutenção (PORT TECHNOLOGY GROUP, 2009). O trabalho de Zen (2005) aborda a corrosão e seus impactos e as práticas de gestão que vem sendo adotadas nas regiões portuárias da Ásia.

A partir de uma investigação ampla e quantitativa, buscou-se com este trabalho contribuir com uma visão geral sobre a corrosão atmosférica no Porto do Açu. A coleta de dados apontou quais são as principais demandas para o direcionamento de esforços que corroborem a minimização deste problema: análise de custos, infraestrutura e equipamentos. A implantação de um sistema de gestão, voltado para esta temática, tem muito a contribuir para o aumento da eficiência dos processos no Porto do Açu. Esta visão deve ser considerada nos futuros projetos de construção que venham a se instalar neste porto, com foco na seleção de materiais mais adequados e técnicas de manutenção específicas (prevenção, predição e correção). $O$ trabalho de NATESAN et al (2006), por exemplo, mostra que nos ambientes portuários da Índia, os materiais feitos de alumínio têm proteção superior em relação ao ferro e ao zinco. No entanto, este padrão não foi confirmado no porto de Mormugao. Por este motivo, a realização de testes com corpos de prova de diferentes materiais convencionalmente usados pelas empresas do porto (aço, aço carbono, aço galvanizado, zinco, etc.) e de produtos anticorrosivos, além da análise de custos, são questões de pesquisa necessárias para subsidiar tomadas decisão de projetos no futuro. 


\section{Conclusões}

A corrosão atmosférica no Porto do Açu começa a gerar impactos para os quais as empresas ainda estão se adaptando a nível de custos e ações preventivas. Os resultados apontados neste trabalho mostram que os problemas da corrosão atmosférica ainda não são considerados pelos gestores como muito relevantes. As ações corretivas estão sendo mais aplicadas do que as ações preventivas, e o estudo demostra um nível intermediário de grau de importância dado pelos gestores ao tema da corrosão. Para que os prejuízos sejam minimizados será preciso que mais estudos e análises sejam desenvolvidos afim de melhor direcionar as empresas e suas ações contra a corrosão no futuro. A aparente falta de estimativa de custos com o problema demonstra que, ou estes não são representativos a ponto de exigirem mais atenção, ou os impactos ainda estão em níveis esperados e aceitáveis mediante a ação da maresia. Um estudo futuro sobre o real impacto financeiro causado pela corrosão no Porto do Açu poderá mensurar de forma mais precisa o problema. 


\section{Referências Bibliográficas}

AHMAD, Z. Principles of corrosion engineering and corrosion control. Elsevier Science \& Technology Books, cap 1, p. 1-2, 2006.

BHASKARAN, R. et al. A review of differing approaches used to estimate the cost of corrosion (and their relevance in the development of modern corrosion prevention and control strategies). Anti-Corrosion Methods and Materials, 52 (1), 29-41, 2005.

FONTANA, M.G. Corrosion engineering. Editora Nace, 1986.

GRANDES CONSTRUÇÕES. Brasil perde 4\% do PIB com corrosão. Revista Grandes Construções, 1-2, 2017.

GENTIL, V. Meios Corrosivos. In. GENTIL, V. Corrosão. Grupo Editorial Nacional, 6a ed., pp. 57-73, 2011.

GIL, A.C. Métodos e técnicas de pesquisa social. Editora Atlas AS, 6ª ed., 2008.

HAYS, G.F. Now is the Time. World Corrosion Organization, Trans Tech Publications www.scientific. net, p. 1, 2010.

HOU, B. et al. The cost of corrosion in China. Npj | Materials Degradation, v. 1, art 4, pp.1-5, 2017. Disponível em < https://www.nature.com/articles/s41529-017-0005-2> Acesso em: 28/02/18.

$\mathrm{KOCH}, \mathrm{G} . \mathrm{H}$. Historic congressional study: corrosion costs and preventive strategies in the united states, p. 3, 2002.

MARCON WORKING GROUP. Life cycle management of port structures recommended practice for implementation. PIANC, Report 103, 2008.

NATESAN, M., VENKATACHARI, G., PALANISWAMY, N. Kinetics of atmospheric corrosion of mild steel, zinc, galvanized iron and aluminium at 10 exposure stations in India. Corrosion Science, 48 (11), 3584-3608, 2006.

NATESAN, M., SELVARAJ, S., MANICKAM, T., VENKATACHARI, G. Corrosion behavior of metals and alloys in marine-industrial environment. Science and Technology of Advanced Materials, 9 (4), 1-7, 2008.

NURAINI, L. et al. Atmospheric corrosion performance of different steels in early exposure in the coastal area region West Java, Indonesia. In: AIP Conference Proceedings. AIP Publishing, 2018. p. 020040.

PEIXOTO, R.L. Conservação e monitorização de estruturas portuárias. 2014.

PORT TECHNOLOGY GROUP, Guidelines on Strategic Maintenance for Port Structures, ASEANJAPAN Transport Partnership, 2009.

PORTAL FATOR BRASIL. Brasil perde 4\% do PIB com corrosão, diz estudo. 22/12/2016. Disponível em: < http://www.revistafatorbrasil.com.br/ver_noticia.php?not=334281\#>. Acesso em: 10 julho, 2017.

PORTELLA, M.O.G. et al. Atmospheric corrosion rates of copper, galvanized steel, carbon steel and aluminum in the metropolitan region of Salvador, BA, Northeast Brazil. Procedia Engineering, 42, 171-185, 2012.

PORTO DO AÇU. Disponível em <http://www.portodoacu.com.br/SitePages/sobre-o-porto/ porto-do-acu.aspx> Acesso em 11/12/2018. 
PRUMO. Prumo Logística Global. Disponível em: http://ri.prumologistica.com.br/default_ pt.asp? idioma $=0 \&$ conta $=28$. Acesso em 01/07/2019.

PRIFIHARNI, S. et al. Corrosion performance of steel and galvanized steel in Karangsong and Limbangan sea water environment. In: AIP Conference Proceedings. AIP Publishing, 2018. p. 020038 .

QUIVY, R.; VAN CAMPENHOUDT, L. Manual de investigação em ciências sociais. P. 5. 1998.

ROBERGE, P.R. Corrosion Engineering: Principles and Practice. McGraw-Hill, cap. 9, p.331, 2008.

UHLIG, H.H. Uhlig's corrosion handbook. John Wiley \& Sons, 2011.

VIANNA, R.O. O programa de corrosão atmosférica desenvolvido pelo CENPES. Boletim Técnico Petrobrás, 23 (1), 39-47, 1980.

ZEN, K. Corrosion and life cycle management of port structures. Corrosion Science, 47 (10), 23532360, 2005. 